HYPOXIA AND REPRODUCTIVE HEALTH

\title{
Hypoxia and ovarian function: follicle development, ovulation, oocyte maturation
}

\author{
Megan Lim ${ }^{1,2,3}$, Jeremy G Thompson ${ }^{1,2,3}$ and Kylie R Dunning ${ }^{1,2,3}$ \\ ${ }^{1}$ Robinson Research Institute, Adelaide Medical School, The University of Adelaide, Adelaide, South Australia, \\ Australia, ${ }^{2}$ Australian Research Council Centre of Excellence for Nanoscale BioPhotonics, The University of \\ Adelaide, Adelaide, South Australia, Australia and ${ }^{3}$ Institute for Photonics and Advanced Sensing, The University of \\ Adelaide, Adelaide, South Australia, Australia \\ Correspondence should be addressed to K R Dunning; Email: kylie.dunning@adelaide.edu.au
}

This paper forms part of a special section on Hypoxia and Reproductive Health. The guest editor for this section was Dr Jacqueline Maybin (University of Edinburgh, UK)

\begin{abstract}
The ovarian follicle provides the oocyte with the ideal environment for growth and development in preparation for ovulation and fertilisation. The follicle undergoes many structural changes as it grows, including changes in vasculature, cell proliferation and differentiation and the formation of a fluid-filled antrum. These changes collectively create a low oxygen environment within the follicle. Thus, the oocyte itself develops in a potentially hypoxic environment. The survival of hypoxic tissues is controlled by hypoxiainducible factors (HIFs) that are activated in a low oxygen state. The understanding of HIF pathways is growing across all fields of biology, and its role in ovarian development is steadily gaining clarity. One of the genes upregulated by HIF is a vascular endothelial growth factor, the main inducer of angiogenesis which is required for follicle development and corpus formation. Ovulation is also intrinsically linked to HIF activity through the ovulatory luteinising hormone surge increasing HIF expression. The role for HIF in oocyte maturation is less understood, as efforts to replicate the low oxygen environment of the in vivo follicle are not achievable by culturing in low oxygen alone. There is potential for other factors present in vivo, but lost in vitro, to be involved in oxygen regulation. One factor of interest is haemoglobin, the oxygen-binding protein, which brings the exciting possibility of sensitive oxygen regulation, consequently affecting HIF-regulated gene expression. A thorough understanding of oxygen regulation within the follicle would provide vital applications for the field of assisted reproductive technologies, in particular in vitro oocyte maturation.

Reproduction (2021) 161 F33-F40
\end{abstract}

\section{Relevance of hypoxia in ovarian biology}

Oxygen is required for the survival of all living things and its deficiency results in the disruption of cellular function. However, many locations within the body exist and function in a physiologically low oxygen state (OrtizPrado et al. 2019). It is now understood that hypoxia $(<6 \%$ oxygen) within organs and tissues increases the level of hypoxia-inducible factors (HIFs) (Wang et al. 1995, Stroka et al. 2001). These transcription factors function as oxygen sensors in the body, governing downstream gene expression and numerous cell processes. The first discoveries in HIFs were made by pioneering researchers in the field of medicine, culminating in the award of the 2019 Nobel Prize in Physiology/Medicine. Their research described the activation of the human erythropoietin gene in response to hypoxia (Semenza \& Wang 1992) leading to developments in the treatment of anaemia (Schodel \& Ratcliffe 2019) and cancers such as Von Hippel-Lindau syndrome (Kaelin 2017).
Around the same time as HIF was discovered, research in the field of reproductive biology revealed the oxygen tension in the follicular fluid of the human ovary decreased as folliculogenesis progressed (Fischer et al. 1992). The ovarian follicle is thought to be adapted to function in low oxygen, with the developing oocyte lying within an entirely avascular environment. The important processes of folliculogenesis, oocyte maturation and ovulation occur in response to hormones such luteinising hormone (LH), follicle-stimulating hormone $(\mathrm{FSH})$, oestradiol and progesterone. There is a clear correlation between low oxygen and hormonal stimulation (van den Driesche et al. 2008, Tam et al. 2010) inducing HIF activity in mouse cumulus-oocyte complexes (COCs), leading to changes in downstream gene expression in the $\mathrm{COC}$ and resulting embryo (Table 1) (Kind et al. 2005, 2015). Importantly, hypoxia also activates the vascular endothelial growth factor (VEGF) gene which is a prime regulator of angiogenesis 
Table 1 Genes expressed upon exposure to hypoxic conditions (low oxygen) and their potential roles in mouse oocyte maturation.

\begin{tabular}{|c|c|c|c|c|}
\hline Cell types & Hypoxia treatment & Genes & Potential roles & References \\
\hline \multirow{6}{*}{ Mouse cumulus cells } & $2 \%$ or $5 \%$ oxygen & & & Kind et al. (2015) \\
\hline & & Slc2a1, Ldha, Eno1, Pgk1 & Glucose uptake and glycolysis & \\
\hline & & Ndrg 1 & Mitochondrial function & \\
\hline & & Bnip3 & Stress protection & \\
\hline & & Elovl6 & Lipid biosynthesis & \\
\hline & & Scd1 1 & Lipid biosynthesis & \\
\hline Mouse primordial germ cell-like cells & $5 \%$ oxygen & Foxo3 & Oocyte dormancy & Shimamoto et al. (2019) \\
\hline
\end{tabular}

Bnip3, BCL2/adenovirus E1B interacting protein 3; Elov/6, elongation of longchain fatty acids family member 6; Eno1, BCL2/adenovirus E1B interacting protein 3; Ldha, lactate dehydrogenase A; Foxo3, forkhead box O3; Ndrg 1, N-myc downstream regulated gene 1; Pgk1,

phosphoglycerate kinase $1 ; S_{c} 1$, stearoyl-CoA desaturase 1; S/c2a1, solute carrier family 2 (facilitated glucose transporter), member 1.

(Liu et al. 1995, Forsythe et al. 1996). Angiogenesis is a key process of ovarian function, particularly during the formation of the corpus luteum $(\mathrm{CL})$ following ovulation (Reynolds \& Redmer 1999, Berisha et al. 2000). Further, at the time of CL formation, additional HIF-regulated genes are induced that are necessary for its development in a variety of species (Table 2) (Meidan et al. 2013, Nishimura \& Okuda 2020).

Much research is now focused on understanding the state of hypoxia in the ovary and applying this to clinical practices, where the implementation of a physiologically low oxygen concentration is beneficial for reproductive success for both mouse and human oocytes (Banwell et al. 2007, Gardner 2016). In vitro follicle culture and oocyte maturation (IVM) practices are increasingly common and provide the opportunity for fertility treatments in women undergoing chemotherapy or experiencing ovarian hyperstimulation syndrome (Brinsden et al. 1995, Das et al. 2012). However, during these procedures, the follicle or oocyte is removed from its in vivo environment and exposed to external environments with vastly different oxygen levels. The rate of successful pregnancies from IVM ranges from 7 to $40 \%$, lower than conventional in vitro fertilisation (Vitek et al. 2013). The relationship between hypoxia and ovarian follicle development is evident, however, this research has yet to be translated to a clinical setting which could bring tangible improvements in IVM success.

\section{A case for low oxygen in the ovary}

Ovarian follicles undergo unique stage-wise structural changes, defining preantral from antral follicles (Fig. 1). At birth, human ovaries have a pool of primordial follicles which each contain the oocyte surrounded by granulosa cells. Upon activation of a primordial follicle into a primary follicle, a zona pellucida is formed around the oocyte and basement membrane around the surrounding granulosa cells. As the granulosa cells multiply and form multiple layers around the oocyte, the secondary follicle begins to develop. Differentiation of interstitial stroma results in the formation of a theca cell layer on the outside of the basement membrane. These structural changes define the preantral stage follicles. At this stage, $\mathrm{FSH}$ and $\mathrm{LH}$ are recognised by receptors on the granulosa and theca cells respectively, initiating the formation of a fluid-filled space among the granulosa cells termed the antrum. The antrum expands and separates the granulosa cells from the oocyte. The granulosa cells lining the follicle wall differentiate into mural granulosa cells and those adjacent to the oocyte differentiate into cumulus cells, forming a COC. A dominant follicle is selected for ovulation and nonselected follicles undergo atresia (Fig. 1). As the COC is separated from granulosa cells by the antrum, and from theca cells and vasculature by the basement membrane, this creates an avascular environment within the antral follicle (Hirshfield 1991). Aside from low oxygen due

Table 2 Genes expressed upon exposure to hypoxic conditions (low oxygen or hypoxia mimetic) and their potential roles in ovulation and folliculogenesis in various animal models.

\begin{tabular}{|c|c|c|c|c|}
\hline Cell types & Hypoxia treatment & Genes & Potential roles & References \\
\hline Rat luteinised granulosa cells & $\mathrm{CoCl}_{2}{ }^{*}$ & Vegfa & $\begin{array}{l}\text { Angiogenesis, cell proliferation } \\
\text { and differentiation }\end{array}$ & Alam et al. (2009) \\
\hline Mouse primary granulosa cells & $\mathrm{CoCl}_{2}$ & Vegfa, Adamts1, Edn2, Cxcr4 & Ovulation & Kim et al. (2009) \\
\hline \multirow[t]{3}{*}{ Bovine granulosa cells } & $1 \%$ oxygen & VEGF, EDN2, PTGS2 & $\begin{array}{l}\text { Angiogenesis, cell proliferation } \\
\text { and differentiation }\end{array}$ & Klipper et al. (2010) \\
\hline & $3 \%$ oxygen & $B N I P 3$ & Luteal formation & Nishimura et al. (2018) \\
\hline & & $S L C 2 A 1$ & Progesterone synthesis & Nishimura et al. (2017) \\
\hline Porcine granulosa cells & $1 \%$ and $5 \%$ oxygen & STC1 & Follicle growth & Basini et al. (2010) \\
\hline
\end{tabular}

${ }^{*} \mathrm{CoCl}_{2}$, cobalt chloride is a hypoxia mimetic.

Adamts 1, a disintegrin and metalloproteinase with thrombospondin-like motifs-1; BNIP3, BCL2/adenovirus E1B interacting protein 3; CXCr4, C-X-C motif receptor 4; Edn2, endothelin-2; PTGS2, prostaglandin-endoperoxide synthase 2; SLC2A1, solute carrier family 2 member 1 ; STC1, Stanniocalcin 1; Vegfa, vascular endothelial growth factor A. 


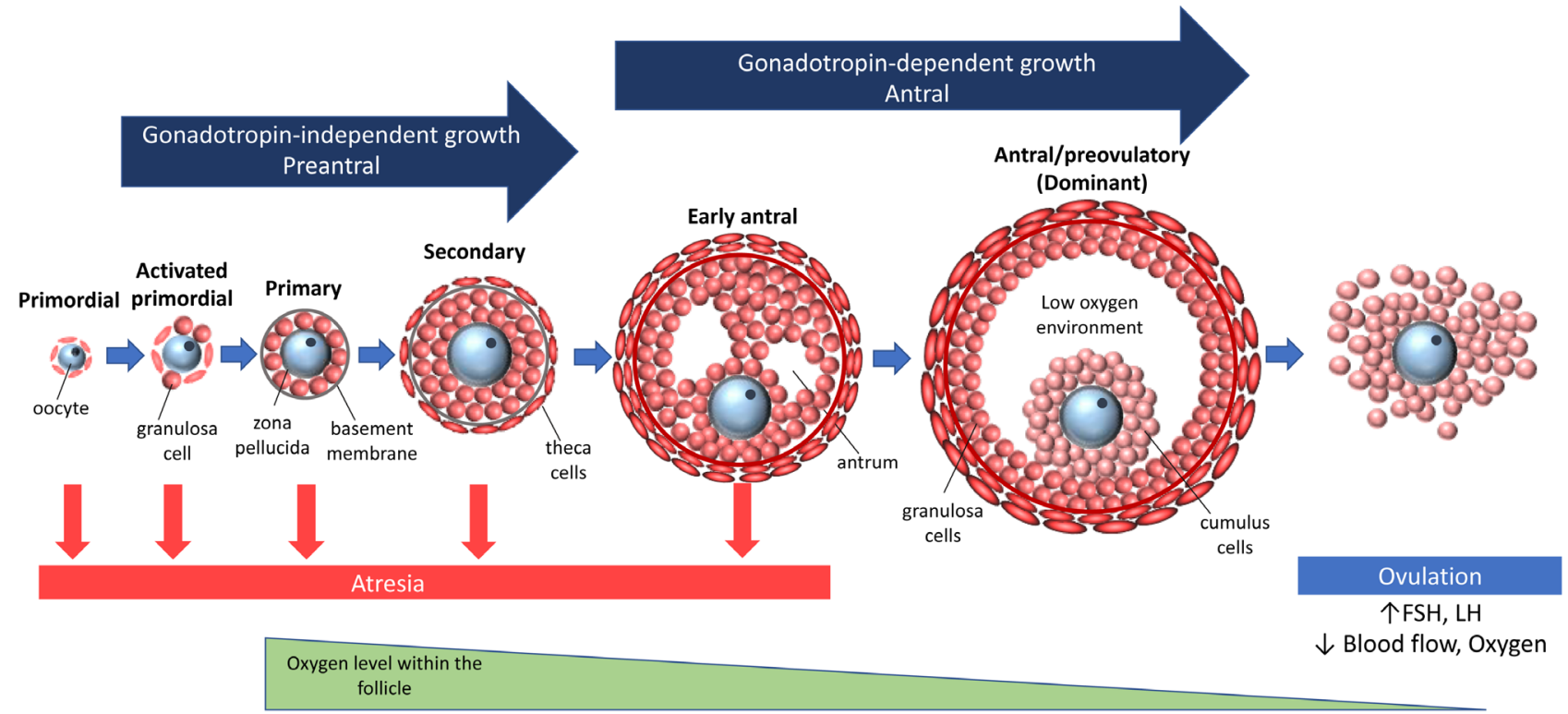

Figure 1 Ovarian follicle development from the primordial to antral follicle stage. As the follicle transitions from preantral, gonadotropinindependent growth, to antral, gonadotropic-dependent growth, the oocyte within the preovulatory follicle is separated from the basement membrane and surrounding blood flow by a large antrum. During folliculogenesis there is an increase in theca cell layers, further separating the vasculature from the basement membrane. This together with antrum formation leads to decreasing oxygen levels within the follicle as it enlarges. Adapted with permission (Leung 2019).

to the structure of the ovary, there is also a decrease in bovine and porcine ovarian blood flow during ovulation (Wise et al. 1982, Magness et al. 1983) suggesting lower oxygen supply to the COC. Through the use of modern 3-D histological analysis, the avascularity of the inner compartment of the follicle in mice was further confirmed (Feng et al. 2017), providing a visual representation of the changes in the vasculature during follicular development (Fraser 2006). Therefore, a thorough understanding of the physiologically low oxygen levels experienced by ovarian cell types, across different stages of follicular development, is critical if we are to replicate this in vitro.

Numerous studies have endeavoured to empirically determine the oxygen levels within the ovarian follicle and understand how oxygen supply is controlled. Measurements of human ovarian follicular fluid oxygen content by aspiration indicated a decrease as follicle development progressed (Fischer et al. 1992). However, once the ovary is removed from the body and follicular fluid aspirated, the exposure to air results in changes in dissolved oxygen levels (Redding et al. 2006). Through the use of mathematical modelling, the oxygen concentration in follicular fluid was determined to be low in both human (Redding et al. 2008) and mouse antral follicles at the preovulatory stage (Clark et al. 2006). Other studies utilised oxygen sensing tools, demonstrating that large porcine follicles had lower levels of oxygen (Basini et al. 2004), which was also observed in bovine preovulatory, antral follicles (de Castro e Paula et al. 2008). This indicates that the diffusion of oxygen towards the oocyte decreases as folliculogenesis progresses, which is supported by low oxygen consumption in cumulus cells (Clark et al. 2006).

\section{Is the ovarian follicle hypoxic?}

There exists a paradox in that while the maturing oocyte resides in an avascular environment, it also relies heavily on oxidative phosphorylation which requires oxygen (Thomson 1967). Thus, avascularity does not necessarily translate to hypoxia, and the follicular environment must compensate for periods that require high oxygen for metabolism. This could be facilitated by the activation of HIF target genes, which are known to be associated with angiogenesis, cell survival and glucose metabolism in other biological systems (Lee et al. 2004). An evaluation of HIF1A protein indicates its presence in granulosa cells of numerous animal models: mouse (Kim et al. 2009), rat (Zhang et al. 2015), bovine (Berisha et al. 2017), porcine (Boonyaprakob et al. 2005) and human (Herr et al. 2004, Henríquez et al. 2017). Furthermore, HIF1A is expressed in mature mouse oocytes and continues to be expressed after fertilisation, from the 2-cell to blastocyst stage (Takahashi et al. 2016).

Hypoxia-inducible factors are members of the basic helix-loop-helix (bHLH)-PAS domain family of transcription factors activated upon hypoxic stress (Semenza \& Wang 1992, Wang et al. 1995). It consists of two subunits: HIF1A, forming part of the HIF1 protein, and HIF1B, also known as aryl hydrocarbon receptor nuclear translocator (ARNT), which bind together forming a heterodimer. The HIF1 protein is the 
regulatory component that binds to hypoxia response elements (HRE) in the promoter of target genes, thereby initiating transcription. Under normoxia, HIF1A is rapidly ubiquitinated and degraded by post-translational hydroxylation (Huang et al. 1998). Therefore, HIF1A has a short half-life of approximately $5 \mathrm{~min}$, which increases to $30 \mathrm{~min}$ in hypoxia as the protein is stabilised (Huang et al. 1998).

Due to its short half-life, studies have utilised transfection reporters to study the action of HIF in the follicle. Experiments on rat granulosa cells cultured in vitro show that HIF is activated by gonadotropins including FSH (Alam et al. 2004, 2009). The addition of human chorionic gonadotropin (hCG) to the in vitro culture of luteinised human granulosa cells in conjunction with hypoxic conditions $(1 \%$ and $5 \%$ oxygen) lead to increased HIF1A and HIF2A expression (Herr et al. 2004, van den Driesche et al. 2008). These hormonal changes are associated with ovulation, and HIF activity also increases in ovulating and differentiating follicles in mice (Tam et al. 2010). This indicates HIF is intimately involved with hormonal changes in the ovary. As the preovulatory, antral follicle shows low levels of HIF activity in the mouse (Kind et al. 2015), it is possible that at that period of development the follicle is not hypoxic in order to support the metabolic requirements of follicle and oocyte (Thompson et al. 2015).

Interestingly, hypoxia is potentially involved in the maintenance of primordial follicles, which contain immature oocytes. In reconstituted ovaries derived from pluripotent stem cells, hypoxia induced oocytes to remain dormant via overexpression of Foxo3 (Shimamoto et al. 2019). Hypoxia also lowers the primordial follicular reserve in rats, potentially due to a reduced capacity for DNA damage and telomere repair (Aiken et al. 2019). The involvement of hypoxia also extends to the other stages of follicular development. There is downregulated HIF1A expression in atretic follicles compared to healthy antral follicles in pigs (Zhang et al. 2018). Hypoxia also limits the growth of bovine follicles in culture through the inhibition of oestrogen receptor (Ma et al. 2019), whereas growth is enhanced upon increasing oxygen supply to mouse follicles (Connolly et al. 2019). This could potentially occur through decreasing levels of VEGF which is most required during the luteal phase after ovulation (Berisha et al. 2000).

\section{The importance of HIF in ovulation}

Ovarian follicle development is often likened to a tumour due to similarities in angiogenesis and levels of VEGF (Neeman et al. 1997). Angiogenesis, the formation of new blood vessels, is triggered by VEGF during follicle development. This leads to increased blood flow and supplies $\mathrm{LH}$ to the growing follicle following induction of VEGF in the theca, granulosa, and cumulus cells of the ovary (Shweiki et al. 1993) (Fig. 2). As angiogenesis is limited to outermost theca cells of the follicle, the avascular environment within the ovary could provide a hypoxic state which increases VEGF levels (Liu et al. 1995) (Fig. 2). Inhibition of VEGF is also capable of upregulating HIF in the primate follicle (Duncan et al. 2008). Recently, it was shown that culturing bovine granulosa cells at low oxygen upregulated genes associated with angiogenesis which are markers of early luteinisation (Baddela et al. 2018). Following hCG induction of ovulation in the mouse, HIF1A and HIF1B were upregulated in granulosa cells: a time when granulosa cells begin their differentiation into luteal cells (Kim et al. 2009). Further, when HIF1A was upregulated in hCG-stimulated luteinised human granulosa cells, there was a similar increase in VEGF gene expression (van den Driesche et al. 2008). Thus, it is evident that both VEGF and HIF have a strong association with one another, as evidenced by hypoxia-induced Vegf gene expression in numerous animal models (Table 2).

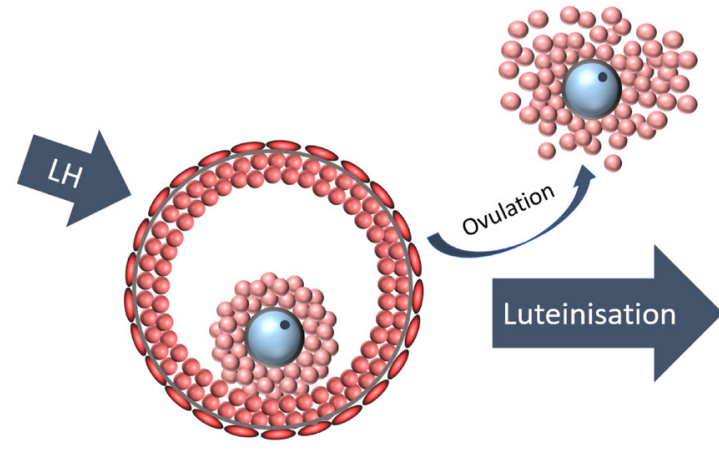

Dominant Follicle

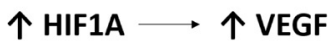

Angiogenesis: Increased LH exposure

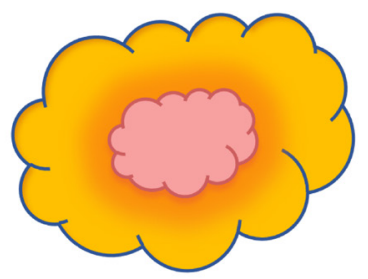

Corpus Luteum

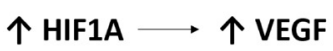

Angiogenesis: Corpus Luteum formation
Figure 2 Association between hypoxia and vascular endothelial growth factor inducing angiogenesis in follicle and corpus luteum development. The low oxygen core of the dominant, antral follicle causes activation of hypoxia-inducible factor 1 alpha (HIF1A) protein and elevated vascular endothelial growth factor (VEGF) (Forsythe et al. 1996). This results in angiogenesis in the outermost cells of the follicle, increasing blood flow to the follicle. The luteinising hormone (LH) surge initiates ovulation of the cumulus-oocyte complex from the dominant follicle. After ovulation, luteinisation is characterised by continued heightened VEGF and HIF1A, resulting in angiogenesis required for corpus luteum formation (Shweiki et al. 1993). 
Expression of HIF1A in response to gonadotropins is also thought to activate downstream processes of steroidogenesis and cell proliferation in granulosa cells which are critical for ovulation (Fadhillah et al. 2017, Baddela et al. 2020).

Angiogenesis is a key process in the formation of the corpus luteum, and HIF activity is maintained following its development in the mouse (Tam et al. 2010) and bovine (Klipper et al. 2010, Nishimura \& Okuda 2010) (Fig. 2). Hypoxia not only signals luteal formation through inducing angiogenesis, but also luteal regression through promoting apoptosis (Nishimura \& Okuda 2015). Emerging studies reveal an inverse relationship between HIF and anti-angiogenic vasohibins in the bovine follicle, indicating one of the many downstream pathways initiated by HIF in corpus luteum progression (Berisha et al. 2017). Therefore, a state of hypoxia is characteristic of the ovarian follicle in preparation for and during luteinisation following ovulation.

\section{The role of HIF during oocyte maturation}

The regulation of oxygen during oocyte maturation has been of great interest since before the discovery of HIFs. The process of IVM provides women with the opportunity of having a baby despite certain medical complications, such as those undergoing chemotherapy or with ovarian hyperstimulation syndrome (Brinsden et al. 1995, Jeruss \& Woodruff 2009). However, the rate of successful pregnancies utilising IVM remains low (Cha et al. 2000, Child et al. 2001, Vitek \& Robins 2013) and IVM-derived oocytes are considered of suboptimal developmental competence due to challenges in replicating the in vivo environment (Eppig et al. 1992, Gilchrist et al. 2011). One major difference in IVM oocytes compared to in vivo oocytes is altered gene expression, as seen in bovine, mouse and human studies (Tesfaye et al. 2009, Kind et al. 2013, Dorfeshan et al. 2018). As discussed, the in vivo ovarian follicle is highly complex in terms of vasculature and morphology, requiring tight regulation of hormones and oxygen, and the COC is likely in a low oxygen environment. By decreasing the oxygen concentration used during IVM of mouse oocytes, there is a marked increase in classic oxygen-regulated genes in cumulus cells of the COC together with HIF1A protein abundance (Kind et al. 2015). Interestingly, in the same study, COCs from in vivo follicles at all stages of development did not show HIF activity contrasted to those derived from IVM at low oxygen concentrations. Thus, the behaviour of HIF in the COC was different in artificial low oxygen surroundings compared to that of the in vivo follicle. An earlier study showed that following IVM of mouse oocytes at low oxygen, fertilisation and embryo developmental outcomes had no effect on the rate of cleavage or blastocyst rates, but increased the ratio of trophectoderm to inner cell mass cells (Banwell et al. 2007). The challenge then is exploring other factors that can be altered to regulate oxygen aside from lowering the oxygen concentration.

\section{The oxygen regulation potential of haemoglobin in the oocyte}

There are a few external factors that affect oxygen regulation in the culture environment, such as glucose concentration (Hashimoto et al. 2000) and the presence of EGF (Preis et al. 2007), which when used in concurrence with low oxygen demonstrate improved oocyte competence. An unexpected factor discovered by our laboratory involves the oxygen-binding protein haemoglobin. Haemoglobin mRNA is present in high levels in mouse cumulus cells following in vivo maturation compared to those from COCs matured in vitro (Kind et al. 2013), as well as in human cumulus cells (Brown et al. 2015). Other upregulated genes included classic HIF-regulated genes which may also play a role in oocyte maturation (Table 1) (Kind et al. 2013). During the course of oocyte maturation in vivo, haemoglobin mRNA expression in mouse cumulus cells peaked at the point of ovulation, indicating hormonal regulation and at a time point associated with increased HIF activity (Brown et al. 2015). The localisation of haemoglobin protein within the oocyte was also altered during maturation in vivo indicating haemoglobin may play a role during oocyte maturation. Haemoglobin is upregulated in several nonerythroid cells that are found in areas that experience hypoxia, such as alveolar epithelial cells (Grek et al. 2011) and glioblastoma cells (Emara et al. 2014), supporting the association of haemoglobin expression with hypoxia in the maturing oocyte.

An important partner molecule of haemoglobin is 2,3-bisphosphoglycerate (2,3-BPG) which binds to the heme group of the protein and facilitates the dissociation of oxygen molecules (Benesch \& Benesch 1967). The synthesis of 2,3-BPG is carried out by the enzyme bisphosphoglycerate mutase (Bpgm). In the in vivo matured mouse COC, Bpgm expression is highest during the periovulatory window, decreasing following ovulation (Brown et al. 2015). An increase in 2,3-BPG is commonly associated with increased demand for oxygen, such as in areas of high altitude (Lenfant et al. 1968). Fetal haemoglobin has a greater affinity for 2,3-BPG to allow oxygen delivery to the growing fetus from the mother (Tomita 1981). Importantly, ovarian granulosa cell tumours have upregulated Bpgm (Owens et al. 2002) which may facilitate oxygen regulation within tumour cells despite it being a hypoxic tissue. As previously stated, oxygen levels are likely to decrease in the follicle as it develops into an antral follicle, placing the oocyte in a low oxygen environment. There is a possibility of an interplay between haemoglobin and 2,3-BPG in the developing oocyte, resulting in HIF activity upon the LH surge which carries through to luteinisation (Thompson et al. 2015) 

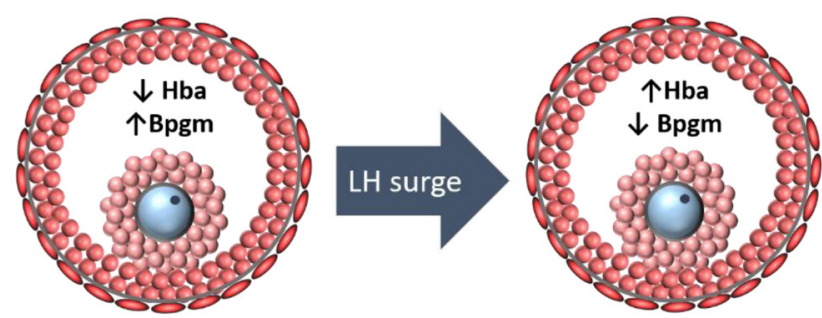

Preovulation:

Low oxygen (non-hypoxic) $\downarrow$ HIF

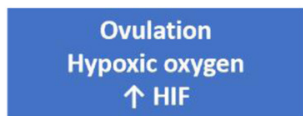

Figure 3 Potential role of haemoglobin in the regulation of hypoxiainducible factors and oxygen. In the preovulatory antral follicle, prior to the luteinising hormone (LH)-surge, there are low levels of haemoglobin (Hba) and high levels of bisphosphoglycerate mutase (Bpgm). This results in low oxygen affinity to $\mathrm{Hba}$, and more oxygen is released from the protein. Thus, oxygen levels are low but not hypoxic, resulting in low levels of hypoxia-inducible factor (HIF) activity. Following the $\mathrm{LH}$ surge, signalling ovulation, there is an increase in $\mathrm{Hba}$ and decrease in Bpgm, resulting in high oxygen affinity to $\mathrm{Hba}$, increasing its oxygen-binding capability. This may result in a decrease in oxygen to hypoxic levels, causing high levels of HIF activity. Adapted with permission (Brown et al. 2015).

(Fig. 3). Haemoglobin could also play important roles in managing oxidative stress and regulating nitric oxide which is required for improved oocyte competence and embryo development (Lim et al. 2018, 2019).

\section{Conclusion}

The ovarian follicle is a highly specialised tissue which requires oxygen for metabolic activity during development, while structurally creating a low oxygen environment for the maturing oocyte within. It is evident that hypoxia plays an important role in facilitating oxygen regulation during follicle development and corpus luteum formation. Gonadotropic signals via FSH and LH which induce ovulation are involved in the maintenance of HIF activity, upregulating VEGF and inducing angiogenesis. Presently, the understanding of low oxygen within the follicle is beset by challenges in measuring oxygen and the differences between in vitro and in vivo matured COCs. The discovery of haemoglobin abundance within the in vivo human and mouse COC provides insight into one of the deficiencies present during IVM that might affect oxygen regulation and oocyte developmental competence. Successful translation of the intricacies of the in vivo ovarian follicle to clinical IVM might improve oocyte developmental capacity and thus provide, a better chance for reproductive success when using this assisted reproductive technology.

\section{Declaration of interest}

The authors declare that there is no conflict of interest that could be perceived as prejudicing the impartiality of this review.

\section{Funding}

K R D is supported by a Mid Career Fellowship from the Hospital Research Foundation (C-MCF-58-2019). This study was funded by the Australian Research Council Centre of Excellence for Nanoscale Biophotonics (CE140100003).

\section{Author contribution statement}

$M L$ wrote the first draft of the manuscript. J G T provided critical feedback on the final manuscript. K R D conceived the review content, provided critical feedback and edited the manuscript. All authors edited and approved the manuscript.

\section{References}

Aiken CE, Tarry-Adkins JL, Spiroski AM, Nuzzo AM, Ashmore TJ, Rolfo A, Sutherland MJ, Camm EJ, Giussani DA \& Ozanne SE 2019 Chronic gestational hypoxia accelerates ovarian aging and lowers ovarian reserve in next-generation adult rats. FASEB Journal 33 7758-7766. (https://doi. org/10.1096/fj.201802772R)

Alam H, Maizels ET, Park Y, Ghaey S, Feiger ZJ, Chandel NS \& HunzickerDunn M 2004 Follicle-stimulating hormone activation of hypoxiainducible factor-1 by the phosphatidylinositol 3-kinase/AKT/Ras homolog enriched in brain (Rheb)/mammalian target of rapamycin (mTOR) pathway is necessary for induction of select protein markers of follicular differentiation. Journal of Biological Chemistry 279 19431-19440. (https://doi.org/10.1074/jbc.M401235200)

Alam H, Weck J, Maizels E, Park Y, Lee EJ, Ashcroft M \& HunzickerDunn M 2009 Role of the phosphatidylinositol-3-kinase and extracellular regulated kinase pathways in the induction of hypoxiainducible factor (HIF)-1 activity and the HIF-1 target vascular endothelial growth factor in ovarian granulosa cells in response to follicle-stimulating hormone. Endocrinology 150 915-928. (https://doi. org/10.1210/en.2008-0850)

Baddela VS, Sharma A, Viergutz T, Koczan D \& Vanselow J 2018 Low oxygen levels induce early luteinization associated changes in bovine granulosa cells. Frontiers in Physiology 9 1066. (https://doi.org/10.3389/ fphys.2018.01066)

Baddela VS, Sharma A, Michaelis M \& Vanselow J 2020 HIF1 driven transcriptional activity regulates steroidogenesis and proliferation of bovine granulosa cells. Scientific Reports 10 3906. (https://doi. org/10.1038/s41598-020-60935-1)

Banwell KM, Lane M, Russell DL, Kind KL \& Thompson JG 2007 Oxygen concentration during mouse oocyte in vitro maturation affects embryo and fetal development. Human Reproduction 22 2768-2775. (https:// doi.org/10.1093/humrep/dem203)

Basini G, Bianco F, Grasselli F, Tirelli M, Bussolati S \& Tamanini C 2004 The effects of reduced oxygen tension on swine granulosa cell. Regulatory Peptides 120 69-75. (https://doi.org/10.1016/j.regpep.2004.02.013)

Basini G, Baioni L, Bussolati S, Grolli S, Kramer LH, Wagner GF \& Grasselli F 2010 Expression and localization of stanniocalcin 1 in swine ovary. General and Comparative Endocrinology 166 404-408. (https:// doi.org/10.1016/j.ygcen.2009.12.013)

Benesch R \& Benesch RE 1967 The effect of organic phosphates from the human erythrocyte on the allosteric properties of hemoglobin. Biochemical and Biophysical Research Communications 26 162-167. (https://doi.org/10.1016/0006-291x(67)90228-8)

Berisha B, Schams D, Kosmann M, Amselgruber W \& Einspanier R 2000 Expression and tissue concentration of vascular endothelial growth factor, its receptors, and localization in the bovine corpus luteum during estrous cycle and pregnancy. Biology of Reproduction 63 1106-1114. (https://doi.org/10.1095/biolreprod63.4.1106)

Berisha B, Schams D, Rodler D, Sinowatz F \& Pfaffl M 2017 Expression pattern of HIF 1alpha and vasohibins during follicle maturation and corpus luteum function in the bovine ovary. Reproduction in Domestic Animals 52 130-139. (https://doi.org/10.1111/rda.12867)

Boonyaprakob U, Gadsby JE, Hedgpeth V, Routh PA \& Almond GW 2005 Expression and localization of hypoxia inducible factor- $1 \alpha$ 
mRNA in the porcine ovary. Canadian Journal of Veterinary Research $69215-222$.

Brinsden PR, Wada I, Tan SL, Balen A \& Jacobs HS 1995 Diagnosis, prevention and management of ovarian hyperstimulation syndrome. British Journal of Obstetrics and Gynaecology 102 767-772. (https://doi. org/10.1111/j.1471-0528.1995.tb10840.x)

Brown HM, Anastasi MR, Frank LA, Kind KL, Richani D, Robker RL, Russell DL, Gilchrist RB \& Thompson JG 2015 Hemoglobin: a gas transport molecule that is hormonally regulated in the ovarian follicle in mice and humans. Biology of Reproduction 92 26. (https://doi. org/10.1095/biolreprod.114.124594)

Cha KY, Han SY, Chung HM, Choi DH, Lim JM, Lee WS, Ko JJ \& Yoon TK 2000 Pregnancies and deliveries after in vitro maturation culture followed by in vitro fertilization and embryo transfer without stimulation in women with polycystic ovary syndrome. Fertility and Sterility $\mathbf{7 3}$ 978-983. (https://doi.org/10.1016/s0015-0282(00)00422-2)

Child TJ, Abdul-Jalil AK, Gulekli B \& Tan SL 2001 In vitro maturation and fertilization of oocytes from unstimulated normal ovaries, polycystic ovaries, and women with polycystic ovary syndrome. Fertility and Sterility 76 936-942. (https://doi.org/10.1016/s0015-0282(01)02853-9)

Clark AR, Stokes YM, Lane M \& Thompson JG 2006 Mathematical modelling of oxygen concentration in bovine and murine cumulusoocyte complexes. Reproduction 131 999-1006. (https://doi. org/10.1530/rep.1.00974)

Connolly JM, Kane MT, Quinlan LR \& Hynes AC 2019 Enhancing oxygen delivery to ovarian follicles by three different methods markedly improves growth in serum-containing culture medium. Reproduction, Fertility, and Development 31 1339-1352. (https://doi.org/10.1071/RD18286)

Das M, Shehata F, Son WY, Tulandi T \& Holzer H 2012 Ovarian reserve and response to IVF and in vitro maturation treatment following chemotherapy. Human Reproduction 27 2509-2514. (https://doi. org/10.1093/humrep/des143)

de Castro e Paula LA, Andrzejewski J, Julian D, Spicer LJ \& Hansen PJ 2008 Oxygen and steroid concentrations in preovulatory follicles of lactating dairy cows exposed to acute heat stress. Theriogenology 69 805-813. (https://doi.org/10.1016/j.theriogenology.2007.12.008)

Dorfeshan P, Ghaffari Novin M, Salehi M, Masteri Farahani R, FadaeiFathabadi F \& Sehatti R 2018 The effects of in vitro maturation technique on the expression of genes involved in embryonic genome activation of human embryos. Cell Journal 20 90-97. (https://doi.org/10.22074/ cellj.2018.4804)

Duncan WC, van den Driesche S \& Fraser HM 2008 Inhibition of vascular endothelial growth factor in the primate ovary up-regulates hypoxiainducible factor- $1 \alpha$ in the follicle and corpus luteum. Endocrinology 149 3313-3320. (https://doi.org/10.1210/en.2007-1649)

Emara M, Turner AR \& Allalunis-Turner J 2014 Hypoxia differentially upregulates the expression of embryonic, fetal and adult hemoglobin in human glioblastoma cells. International Journal of Oncology 44 950-958. (https://doi.org/10.3892/ijo.2013.2239)

Eppig JJ, Schroeder AC \& O'Brien MJ 1992 Developmental capacity of mouse oocytes matured in vitro: effects of gonadotrophic stimulation, follicular origin and oocyte size. Journal of Reproduction and Fertility 95 119-127. (https://doi.org/10.1530/jrf.0.0950119)

Fadhillah, Yoshioka S, Nishimura R, Yamamoto Y, Kimura K \& Okuda K 2017 Hypoxia-inducible factor 1 mediates hypoxia-enhanced synthesis of progesterone during luteinization of granulosa cells. Journal of Reproduction and Development 63 75-85. (https://doi.org/10.1262/ jrd.2016-068)

Feng Y, Cui P, Lu X, Hsueh B, Möller Billig F, Zarnescu Yanez L, Tomer R, Boerboom D, Carmeliet P, Deisseroth K et al. 2017 Clarity reveals dynamics of ovarian follicular architecture and vasculature in threedimensions. Scientific Reports 7 44810. (https://doi.org/10.1038/ srep44810)

Fischer B, Kunzel W, Kleinstein J \& Gips H 1992 Oxygen tension in follicular fluid falls with follicle maturation. European Journal of Obstetrics, Gynecology, and Reproductive Biology 43 39-43. (https:// doi.org/10.1016/0028-2243(92)90241-p)

Forsythe JA, Jiang BH, Iyer NV, Agani F, Leung SW, Koos RD \& Semenza GL 1996 Activation of vascular endothelial growth factor gene transcription by hypoxia-inducible factor 1. Molecular and Cellular Biology 16 4604-4613. (https://doi.org/10.1128/mcb.16.9.4604)
Fraser HM 2006 Regulation of the ovarian follicular vasculature. Reproductive Biology and Endocrinology 4 18. (https://doi. org/10.1186/1477-7827-4-18)

Gardner DK 2016 The impact of physiological oxygen during culture, and vitrification for cryopreservation, on the outcome of extended culture in human IVF. Reproductive Biomedicine Online 32 137-141. (https://doi. org/10.1016/j.rbmo.2015.11.008)

Gilchrist RB, De Vos M, Smitz J \& Thompson JG 2011 IVM media are designed specifically to support immature cumulus-oocyte complexes not denuded oocytes that have failed to respond to hyperstimulation. Fertility and Sterility 96 e141. (https://doi.org/10.1016/j.fertnstert.2011.06.012)

Grek CL, Newton DA, Spyropoulos DD \& Baatz JE 2011 Hypoxia upregulates expression of hemoglobin in alveolar epithelial cells. American Journal of Respiratory Cell and Molecular Biology 44 439-447. (https:// doi.org/10.1165/rcmb.2009-0307OC)

Hashimoto S, Minami N, Takakura R, Yamada M, Imai H \& Kashima N 2000 Low oxygen tension during in vitro maturation is beneficial for supporting the subsequent development of bovine cumulusoocyte complexes. Molecular Reproduction and Development $\mathbf{5 7}$ 353-360. (https://doi.org/10.1002/1098-2795(200012)57:4<353::AIDMRD7>3.0.CO;2-R)

Henríquez S, Kohen P, Muñoz A, Godoy A, Orge F, Strauss III JF \& Devoto L 2017 In-vitro study of gonadotrophin signaling pathways in human granulosa cells in relation to progesterone receptor expression. Reproductive Biomedicine Online 35 363-371. (https://doi. org/10.1016/j.rbmo.2017.06.011)

Herr D, Keck C, Tempfer C \& Pietrowski D 2004 Chorionic gonadotropin regulates the transcript level of VHL, p53, and HIF- $2 \alpha$ in human granulosa lutein cells. Molecular Reproduction and Development 69 397-401. (https://doi.org/10.1002/mrd.20137)

Hirshfield AN 1991 Development of follicles in the mammalian ovary. International Review of Cytology 124 43-101. (https://doi.org/10.1016/ s0074-7696(08)61524-7)

Huang LE, Gu J, Schau M \& Bunn HF 1998 Regulation of hypoxia-inducible factor 1alpha is mediated by an O2-dependent degradation domain via the ubiquitin-proteasome pathway. PNAS 95 7987-7992. (https://doi. org/10.1073/pnas.95.14.7987)

Jeruss JS \& Woodruff TK 2009 Preservation of fertility in patients with cancer. New England Journal of Medicine 360 902-911. (https://doi. org/10.1056/NEJMra0801454)

Kaelin Jr WG 2017 The VHL tumor suppressor gene: insights into oxygen sensing and cancer. Transactions of the American Clinical and Climatological Association 128 298-307.

Kim J, Bagchi IC \& Bagchi MK 2009 Signaling by hypoxia-inducible factors is critical for ovulation in mice. Endocrinology 150 3392-3400. (https:// doi.org/10.1210/en.2008-0948)

Kind KL, Collett RA, Harvey AJ \& Thompson JG 2005 Oxygen-regulated expression of GLUT-1, GLUT-3, and VEGF in the mouse blastocyst. Molecular Reproduction and Development 70 37-44. (https://doi. org/10.1002/mrd.20183)

Kind KL, Banwell KM, Gebhardt KM, Macpherson A, Gauld A, Russell DL \& Thompson JG 2013 Microarray analysis of mRNA from cumulus cells following in vivo or in vitro maturation of mouse cumulus-oocyte complexes. Reproduction, Fertility, and Development 25 426-438. (https://doi.org/10.1071/RD11305)

Kind KL, Tam KK, Banwell KM, Gauld AD, Russell DL, Macpherson AM, Brown HM, Frank LA, Peet DJ \& Thompson JG 2015 Oxygen-regulated gene expression in murine cumulus cells. Reproduction, Fertility, and Development 27 407-418. (https://doi.org/10.1071/RD13249)

Klipper E, Levit A, Mastich Y, Berisha B, Schams D \& Meidan R 2010 Induction of endothelin-2 expression by luteinizing hormone and hypoxia: possible role in bovine corpus luteum formation. Endocrinology 151 1914-1922. (https://doi.org/10.1210/en.2009-0767)

Lee JW, Bae SH, Jeong JW, Kim SH \& Kim KW 2004 Hypoxia-inducible factor (HIF-1)alpha: its protein stability and biological functions. Experimental and Molecular Medicine 36 1-12. (https://doi.org/10.1038/emm.2004.1)

Lenfant C, Torrance J, English E, Finch CA, Reynafarje C, Ramos J \& Faura J 1968 Effect of altitude on oxygen binding by hemoglobin and on organic phosphate levels. Journal of Clinical Investigation 47 2652-2656. (https:// doi.org/10.1172/JCI105948)

Leung PCK 2019 The Ovary, 3rd ed. Academic Press. 
Lim M, Brown HM, Kind KL, Breen J, Anastasi MR, Ritter LJ, Tregoweth EK, Dinh DT, Thompson JG \& Dunning KR 2018 Haemoglobin expression in in vivo murine preimplantation embryos suggests a role in oxygenregulated gene expression. Reproduction, Fertility, and Development 31 724-734. (https://doi.org/10.1071/RD17321)

Lim M, Brown HM, Kind KL, Thompson JG \& Dunning KR 2019 Hemoglobin: potential roles in the oocyte and early embryo. Biology of Reproduction 101 262-270. (https://doi.org/10.1093/biolre/ioz078)

Liu Y, Cox SR, Morita T \& Kourembanas S 1995 Hypoxia regulates vascular endothelial growth factor gene expression in endothelial cells. Identification of a 5' enhancer. Circulation Research 77 638-643. (https://doi.org/10.1161/01.res.77.3.638)

Ma L, Wang L, Gao H, Liu N, Zheng Y, Gao Y, Liu S \& Jiang Z 2019 Hypoxia limits the growth of bovine follicles in vitro by inhibiting estrogen receptor alpha. Animals 9 551. (https://doi.org/10.3390/ani9080551)

Magness RR, Christenson RK \& Ford SP 1983 Ovarian blood flow throughout the estrous cycle and early pregnancy in sows. Biology of Reproduction 28 1090-1096. (https://doi.org/10.1095/biolreprod28.5.1090)

Meidan R, Klipper E, Zalman Y \& Yalu R 2013 The role of hypoxia-induced genes in ovarian angiogenesis. Reproduction, Fertility, and Development 25 343-350. (https://doi.org/10.1071/RD12139)

Neeman M, Abramovitch R, Schiffenbauer YS \& Tempel C 1997 Regulation of angiogenesis by hypoxic stress: from solid tumours to the ovarian follicle. International Journal of Experimental Pathology 78 57-70. (https://doi.org/10.1046/j.1365-2613.1997.d01-247.x)

Nishimura R \& Okuda K 2010 Hypoxia is important for establishing vascularization during corpus luteum formation in cattle. Journal of Reproduction and Development 56 110-116. (https://doi.org/10.1262/ jrd.09-162e)

Nishimura R \& Okuda K 2015 Multiple roles of hypoxia in ovarian function: roles of hypoxia-inducible factor-related and -unrelated signals during the luteal phase. Reproduction, Fertility, and Development $\mathbf{2 8}$ 1479-1486. (https://doi.org/10.1071/RD15010)

Nishimura R \& Okuda K 2020 Multiple roles of hypoxia in bovine corpus luteum. Journal of Reproduction and Development 66 307-310. (https:// doi.org/10.1262/jrd.2020-018)

Nishimura R, Hasegawa H, Yamashita M, Ito N, Okamoto Y, Takeuchi T, Kubo T, Iga K, Kimura K, Hishinuma M et al. 2017 Hypoxia increases glucose transporter 1 expression in bovine corpus luteum at the early luteal stage. Journal of Veterinary Medical Science 79 1878-1883. (https://doi.org/10.1292/jvms.17-0284)

Nishimura R, Okuda K, Gunji Y, Khalid AM, Yamano Y, Yamashita Y \& Hishinuma M 2018 BNIP3 expression in bovine follicle and corpus luteum. Journal of Veterinary Medical Science 80 368-374. (https://doi. org/10.1292/jvms.17-0267)

Ortiz-Prado E, Dunn JF, Vasconez J, Castillo D \& Viscor G 2019 Partial pressure of oxygen in the human body: a general review. American Journal of Blood Research 9 1-14.

Owens GE, Keri RA \& Nilson JH 2002 Ovulatory surges of human CG prevent hormone-induced granulosa cell tumor formation leading to the identification of tumor-associated changes in the transcriptome. Molecular Endocrinology 16 1230-1242. (https://doi.org/10.1210/ mend.16.6.0850)

Preis KA, Seidel Jr GE \& Gardner DK 2007 Reduced oxygen concentration improves the developmental competence of mouse oocytes following in vitro maturation. Molecular Reproduction and Development $\mathbf{7 4}$ 893-903. (https://doi.org/10.1002/mrd.20655)

Redding GP, Bronlund JE \& Hart AL 2006 The effects of IVF aspiration on the temperature, dissolved oxygen levels, and $\mathrm{pH}$ of follicular fluid. Journal of Assisted Reproduction and Genetics 23 37-40. (https://doi. org/10.1007/s10815-005-9011-3)

Redding GP, Bronlund JE \& Hart AL 2008 Theoretical investigation into the dissolved oxygen levels in follicular fluid of the developing human follicle using mathematical modelling. Reproduction, Fertility, and Development 20 408-417. (https://doi.org/10.1071/rd07190)

Reynolds LP \& Redmer DA 1999 Growth and development of the corpus luteum. Journal of Reproduction and Fertility: Supplement 54 181-191. (https://doi.org/10.1530/biosciprocs.4.014)

Schodel J \& Ratcliffe PJ 2019 Mechanisms of hypoxia signalling: new implications for nephrology. Nature Reviews: Nephrology 15 641-659. (https://doi.org/10.1038/s41581-019-0182-z)

Semenza GL \& Wang GL 1992 A nuclear factor induced by hypoxia via de novo protein synthesis binds to the human erythropoietin gene enhancer at a site required for transcriptional activation. Molecular and Cellular Biology 12 5447-5454. (https://doi.org/10.1128/ mcb.12.12.5447)

Shimamoto S, Nishimura Y, Nagamatsu G, Hamada N, Kita H, Hikabe O, Hamazaki N \& Hayashi K 2019 Hypoxia induces the dormant state in oocytes through expression of Foxo3. PNAS 116 12321-12326. (https:// doi.org/10.1073/pnas.1817223116)

Shweiki D, Itin A, Neufeld G, Gitay-Goren H \& Keshet E 1993 Patterns of expression of vascular endothelial growth factor (VEGF) and VEGF receptors in mice suggest a role in hormonally regulated angiogenesis. Journal of Clinical Investigation 91 2235-2243. (https://doi.org/10.1172/ JCI116450)

Stroka DM, Burkhardt T, Desbaillets I, Wenger RH, Neil DA, Bauer C, Gassmann M \& Candinas D 2001 HIF-1 is expressed in normoxic tissue and displays an organ-specific regulation under systemic hypoxia. FASEB Journal 15 2445-2453. (https://doi.org/10.1096/fj.01-0125com)

Takahashi N, Davy PM, Gardner LH, Mathews J, Yamazaki Y \& Allsopp RC 2016 Hypoxia inducible factor 1 alpha is expressed in germ cells throughout the murine life cycle. PLOS ONE 11 e0154309. (https://doi. org/10.1371/journal.pone.0154309)

Tam KKY, Russell DL, Peet DJ, Bracken CP, Rodgers RJ, Thompson JG \& Kind KL 2010 Hormonally regulated follicle differentiation and luteinization in the mouse is associated with hypoxia inducible factor activity. Molecular and Cellular Endocrinology 327 47-55. (https://doi. org/10.1016/j.mce.2010.06.008)

Tesfaye D, Ghanem N, Carter F, Fair T, Sirard MA, Hoelker M, Schellander K \& Lonergan P 2009 Gene expression profile of cumulus cells derived from cumulus-oocyte complexes matured either in vivo or in vitro. Reproduction, Fertility, and Development 21 451-461. (https:// doi.org/10.1071/rd08190)

Thompson JG, Brown HM, Kind KL \& Russell DL 2015 The ovarian antral follicle: living on the edge of hypoxia or not? Biology of Reproduction 92 153. (https://doi.org/10.1095/biolreprod.115.128660)

Thomson JL 1967 Effect of inhibitors of carbohydrate metabolism on the development of preimplantation mouse embryos. Experimental Cell Research 46 252-262. (https://doi.org/10.1016/0014-4827(67)900638)

Tomita S 1981 Modulation of the oxygen equilibria of human fetal and adult hemoglobins by 2,3-diphosphoglyceric acid. Journal of Biological Chemistry 256 9495-9500.

van den Driesche S, Myers M, Gay E, Thong KJ \& Duncan WC 2008 HCG up-regulates hypoxia inducible factor-1 alpha in luteinized granulosa cells: implications for the hormonal regulation of vascular endothelial growth factor $\mathrm{A}$ in the human corpus luteum. Molecular Human Reproduction 14 455-464. (https://doi.org/10.1093/molehr/gan040)

Vitek W \& Robins JC 2013 In vitro maturation. Obstetrician and Gynaecologist 15 215-219. (https://doi.org/10.1111/tog.12050)

Wang GL, Jiang BH, Rue EA \& Semenza GL 1995 Hypoxia-inducible factor 1 is a basic-helix-loop-helix-PAS heterodimer regulated by cellular O2 tension. PNAS 92 5510-5514. (https://doi.org/10.1073/ pnas.92.12.5510)

Wise TH, Caton D, Thatcher WW, Barron DH \& Fields MJ 1982 Ovarian function during the estrous cycle of the cow: ovarian blood flow and progesterone release rate. Journal of Animal Science 55 627-637. (https://doi.org/10.2527/jas1982.553627x)

Zhang ZH, Chen LY, Wang F, Wu YQ, Su JQ, Huang XH, Wang ZC \& Cheng Y 2015 Expression of hypoxia-inducible factor- $1 \alpha$ during ovarian follicular growth and development in Sprague-Dawley rats. Genetics and Molecular Research 14 5896-5909. (https://doi.org/10.4238/2015. June.1.7)

Zhang J, Liu Y, Yao W, Li Q, Liu H \& Pan Z 2018 Initiation of follicular atresia: gene networks during early atresia in pig ovaries. Reproduction 156 23-33. (https://doi.org/10.1530/REP-18-0058)

Received 10 September 2020

First decision 23 October 2020

Revised Manuscript received 7 November 2020

Accepted 12 November 2020 